\title{
Thyroid hormone responses to acute aerobic exercise
}

\author{
Mustafa S. Akgul ${ }^{\mathrm{ABCDE}}$, Bilgehan Baydil ${ }^{2 \mathrm{ABCDE}}$ \\ ${ }^{1}$ Hasan Dogan School of Physical Education and Sports, Karabuk University, Turkey \\ ${ }^{2}$ Faculty of Sports Science, Kastamonu University, Turkey
}

Authors' Contribution: A - Study design; B - Data collection; C - Statistical analysis; D - Manuscript Preparation; E - Funds Collection.

\begin{abstract}
Background Thyroid hormone responses to acute maximal aerobic exercise is still unclear, so the aim of the study is to and Study Aim investigate the effect of acute maximal aerobic exercise resulting in fatigue on blood thyroid levels in men and women.

Material and The study included 8 male and 7 female subjects who did not actively exercise. Both group participants Methods were students in the Kastamonu University in the period of study. The heights, weights, resting hearth rates and $5 \mathrm{cc}$. venous blood samples of subjects were taken before the exercise. The subjects warmed up for ten minutes before they had $20 \mathrm{~m}$ shuttle run. The purpose of this test was to tire the subjects to the exhaustion. The heart rate were measured at the end of the test in order to determine the exhaustion levels of the participants. The $5 \mathrm{cc}$. venous blood samples were taken again just after the exhaustion exercise. Statistical analysis was carried out using Statistical Package for the Social Sciences (SPSS) 23 program (SPSS Inc. Chicago. II. USA). P value was set at $\mathrm{p}<0.05$.

Results When results were compared between both sexes, no significant difference was found among variables ( $p>0.05$ ). There was significant change in TSH values in all group. They increased following the exercise compared to pre-exercise values. Moreover, total T3 decreased in all group. No other significant difference was found in free $\mathrm{T} 3$ and free T4 variables.

Conclusions In conclusion, thyroid responses to exercise emerge in a very complex way, which makes it difficult to reach a clear conclusion about its effects. The reason why the results are so contradictory is that the duration and intensity of the exercise, age, not being able to control the diet, and the timing of collection of blood samples after exercise.

Keywords: $\quad$ aerobic exercise, fatigue, thyroid stimulating hormone
\end{abstract}

\section{Introduction}

It is a well-known fact that exercise affects many glands and the hormones they secrete. One of these affected hormones is thyroid [1]. Thyroid stimulating hormone (TSH) secreted from the pituitary gland is responsible for keeping the basal thyroid levels in the circulation constant by increasing or decreasing the release levels [2]. Thyrotropin releasing hormone (TRH) release from the hypothalamus stimulates the release of TSH from the anterior pituitary gland, which affects the release of triiodothyronine (T3) and thyroxine (T4) [3]. The major thyroid hormones T4 and T3 are critical for normal physiological functions throughout life. This is especially true for $\mathrm{T} 3$, the biologically active form of thyroid hormones [4]. These hormones have important effects on growth and development, temperature regulation, oxygen consumption [5], energy metabolism, carbohydrate metabolism and cardiac functions [2].

Some hormonal adjustments are required to balance the physical stress caused by exercise and its effects. Although there are studies in the literature that vigorous exercise causes an increase in T3 and T4 levels [6], the results are controversial and it is thought to be variable according to the duration and intensity of the exercise [7], ambient temperature and training status [8]. It is also known that thyroid hormones increase basal metabolic

(c) Mustafa S. Akgul, Bilgehan Baydil, 2021

doi:10.15561/20755279.2021.0604 rate, protein synthesis and the effect of catecholamines. However, responses of thyroid hormones to different types of exercise are not clear. There are studies showing that aerobic exercise increases $\mathrm{T} 3$ and $\mathrm{T} 4$ depending on the intensity [9] However, studies showing that thyroid hormones do not increase acutely during exercise are also presented in the literature. It has been revealed that thyroid hormones exhibit inconsistent changes during long-term exercise periods [10]. The role of thyroid hormones during resistance training is unclear, but there are studies on their interactions with other hormones. Studies on moderately trained individuals and highly trained rowers have reported that T4 hormone, fT4 (free thyroxin in plasma) [11] and fT3 (free triiodothyronine in plasma) and TSH [12] levels significantly decreased in resting state.

In the light of abovementioned information, the aim of the study is to investigate the effect of acute maximal aerobic exercise resulting in fatigue on blood thyroid levels in men and women.

\section{Materials and Methods}

\section{Participants}

The study included 8 male and 7 female subjects who did not actively exercise. Both group participants were students in the Kastamonu University in the period of study. The mean age of the subjects was $21.16 \pm 1.49$ years, average antropometric measurements are as follows 
(Table 1) height of $173.62 \pm 3.87 \mathrm{~cm}$, weight of 69.97 $\pm 7.32 \mathrm{~kg}$. All subjects were informed about the purpose and procedures of the study. For the standardize dietary, subjects were asked to obey dietitians advisement before exercise 3 days ago.

\section{Research Design}

The heights, weights, resting hearth rates and $5 \mathrm{cc}$. venous blood samples of subjects were taken before the exercise. The subjects warmed up for ten minutes before they had $20 \mathrm{~m}$ shuttle run. The purpose of this test was to tire the subjects to the exhaustion. The criterion to end the exercise was that subjects classified rate of perceived exertion at least 18 according to Borg scale [13]. The heart rate were measured at the end of the test in order to determine the exhaustion levels of the participants. The 5 cc. venous blood samples were taken again just after the exhaustion exercise.

Statistical Analysis

Mean values, standard deviation and 95\% confidence intervals of the variables were calculated. Normality of the variables were validated using the Shapiro-Wilk test. Paired sample T-test was used to examine within-group changes while Independent Sample T-test was used to compare genders. Statistical analysis was carried out using Statistical Package for the Social Sciences (SPSS) 23 program (SPSS Inc. Chicago. II. USA). P value was set at $\mathrm{p}<0.05$.

\section{Results}

Mean values, standard deviation and $95 \%$ confidence intervals of the variables are presented in Table 2. When results were compared between both sexes, no significant difference was found among variables $(p>0.05)$. There was significant change in TSH values in all group. They increased following the exercise compared to pre-exercise values. Moreover, total T3 decreased in all group. No other significant difference was found in free T3 and free $\mathrm{T} 4$ variables.

Table 1. Some of physical and physiological parameters of the participants

\begin{tabular}{lcc}
\hline Parameters & N & Mean (X) \\
\hline Age (year) & 15 & $21.16 \pm 1.49$ \\
Height (cm) & 15 & $173.62 \pm 3.87$ \\
Body Weight (kg) & 15 & $69.97 \pm 7.32$ \\
Resting Hearth Rate(beat/min.) & 15 & $77.16 \pm 7.36$ \\
Max VO (mL.kg/min) & 15 & $35.42 \pm 4.26$ \\
\hline
\end{tabular}

Table 2. Changes in variables pre and post training

\begin{tabular}{|c|c|c|c|}
\hline Variables & Mean士SD & $\mathbf{t}$ & $\mathbf{p}$ \\
\hline 1st TSH (ulU/ml) & $1.46 \pm 0.43$ & & \\
\hline 2nd TSH (ulU/ml) & $2.00 \pm 0.71$ & -6.011 & $0.000 *$ \\
\hline 1st FREE T3 (pmol/l) & $5.37 \pm 0.44$ & & \\
\hline 2nd FREE T3 (pmol/l) & $5.28 \pm 0.40$ & 1.093 & 0.292 \\
\hline 1st FREE T4 (ng/dl) & $1.34 \pm 0.20$ & & \\
\hline 2nd FREE T4 (ng/dl) & $1.31 \pm 0.21$ & 1.345 & 0.199 \\
\hline 1st TOTAL T3 (nmol/l) & $114.11 \pm 21.69$ & & \\
\hline 2nd TOTAL T3 (nmol/l) & $106.50 \pm 19.74$ & 2.474 & $0.026 *$ \\
\hline 1st TOTAL T4 (ng/dl) & $\begin{array}{l}9.01 \pm 1.27 \\
9.42 \pm 1.27\end{array}$ & -1.812 & 0.090 \\
\hline
\end{tabular}

Note: * - $p<0.05$; TSH - thyroid stimulating hormone; FREE T3 - free triiodothyronine in plasma; FREE T4 - free thyroxin in plasma; T3 - triiodothyronine; T4 - thyroxine. 


\section{Discussion}

Thyroid hormones play an important role in meeting the metabolic needs that increase with exercise, and these hormonal changes can be observed immediately after exercise and in the following hours [7]. When the results of our study were examined, no significant difference was found between genders in the parameters tested ( $p>0.05)$. In statistical analysis conducted regardless of gender difference, it was observed that the increase in TSH hormone and the decrease in the Total T3 parameter were significant $(\mathrm{p}<0.05)$, but the difference in other parameters was not statistically significant (Table 2),

Considering the studies conducted on the effects of exercise on thyroid parameters in the literature, it is seen that it is very difficult to collect the results into a single point which are thought to differ due to the variability of external factors, For this reason, there are studies that support the results in the literature as we have obtained, as well as studies in the opposite direction. In the study conducted by Sullo et al. it was found that strenuous swimming exercise caused an increase in serum TSH levels and significant decreases in Total T3 and Total T4 in rats [14]. In the study conducted by Galbo et al on 8 men, the thyroid responses to exercises with gradually increasing workloads $(47 \%, 77 \%$, and $100 \%$ of MaxVO2) and to exercise up to prolonged fatigue were examined. As a result, significant increases in TSH levels were observed $(\mathrm{P}<0.001)$, but no significant difference was found in T3 and T4 levels [15]. In the study by Kilic et al., in which they examined the effects of exhausting cycling exercise performed on 10 sedentary men on thyroid and testosterone hormones, they reported significant decreases in total T3, total T4 and free T3 levels after exercise $(p<0.01)$. However, they did not detect a significant difference between TSH and free T4 [16]. In the study conducted by Bosco et al. on 16 men who are professionally engaged in sports, it was found that there was a significant increase of $20 \%$ for TSH, $28 \%$ for free T3 and $30 \%$ for free T 4 after the exhausting Bosco test of 60 seconds $(p<0.05)$ [17]. In the study conducted by Huang et al., 26 healthy men were subjected to Bruce protocol with treadmill and examined the thyroid responses that emerged immediately after and after maximal exercise. As a result, they stated that the change in T3 and T4 parameters was not statistically significant, but the increase in TSH level was significant $(p<0.01)$ [18]. Ciloglu et al. investigated the effects of exercise intensity on thyroid hormones and found that high intensity acute aerobic exercise with $90 \%$ of the maximum number of heartbeats caused higher TSH responses compared to $45 \%$ of the maximum number of heartbeats. However, significant reductions were also detected in total and free T3 levels [1]. In another study by Beyleroglu, in which thyroid responses emerging after acute aerobic exercise were examined, it was found that TSH and fT3 levels were found to be significantly decreased, but no change was observed in the fT3 level [19]. Sowers et al. reported that exercise-induced glucocorticoid increases may be a factor that stimulates TSH increase and T3 decrease [20]. Moore et al. are known to suppress thyroid functions of glucocorticoids such as cortisol. As a matter of fact, in their research, they examined the relationship between cortisol and thyroid hormones in strenuous exercises; they found a significant increase in TSH and fT3 levels right after running with about $75 \%$ of Max VO2, which continued until fatigue was reached [21]. In another study by Hesse et al., the thyroid responses to three different running distances $(75 \mathrm{~km}, 45 \mathrm{~km}, 42.2 \mathrm{~km})$ were examined. They found an increase in T4 in $75 \mathrm{~km}$. and $42.2 \mathrm{~km}$. groups while they found a decrease in T4 level in $45 \mathrm{~km}$. group. Likewise, while a decrease in T3 level in $45 \mathrm{~km}$. group was observed, an increase was observed in the other groups [22].

As in the studies mentioned above, there are many studies in the literature that mention the positive effect of exercise on TSH [23, 24, 25, 26, 27]. However, there are studies indicating that there is a decrease in TSH level or that the change cannot be detected [16, 28, 29, 30, 31, 32]. As in the different results observed in the TSH parameter, there are studies that mentioned decrease in T3 level [16, $27,32]$ and increase in reverse $[10,31]$.

\section{Conclusions}

In conclusion, thyroid responses to exercise emerge in a very complex way, which makes it difficult to reach a clear conclusion about its effects. The reason why the results are so contradictory is that the duration and intensity of the exercise, age, not being able to control the diet and the blood samples after exercise.

\section{Acknowledgments}

The authors sincerely thank the subjects, who participated in this study and contributed to the realization of this study. This research received no funding.

\section{Conflicts of Interest}

The authors declare no conflict of interest. 


\section{References}

1. Ciloglu F, Peker I, Pehlivan A, Karacabey K, Ilhan N, Saygin O, et al. Exercise intensity and its effects on thyroid hormones. Neuro Endocrinol Lett, 2005;26:830-4.

2. Ak1l M, Kara E, Bicer M, Acat M. Effects of submaximal exercise on thyroid hormone metabolism in sedentary individuals. Nigde University Journal of Physical Education And Sport Sciences, 2011;5(1):28-32. https://doi.org/10.1007/s00421-002-0737-7

3. Hackney AC, Kallman A, Hosick KP, Rubin DA, Battaglini CL. Thyroid hormonal responses to intensive interval versus steady-state endurance exercise sessions. Hormones (Athens), 2012;11(1):54-60. https://doi.org/10.1007/BF03401537

4. Yen PM, Physiological and molecular basis of thyroid hormone action. Physiological Reviews, 2001;81(3):1097-1126. https://doi.org/10.1152/physrev.2001.81.3.1097

5. Cinar V, Akbulut T, Sarikaya M. Effect of zinc supplement and weight lifting exercise on thyroid hormone levels. Indian J. Physiol. Pharmacol., 2017;61(3):232-236.

6. Fortunato RS, Ignácio DL, Padron ÁS, Peçanha R, Marassi MP, Rosenthal D, et al. The effect of acute exercise session on thyroid hormone economy in rats. Journal of Endocrinology, 2008;198:347-53. https://doi.org/10.1677/JOE-08-0174

7. Warren MP, Constantini NW. Sports Endocrinology. vol. 23. New Jersey: Humana Press; 2000. https://doi.org/10.1385/1592590160

8. Ratamess NA. ACSM's Foundations of Strength Training and Conditioning. Philadelphia: Wolters Kluwer Health/ Lippincott Williams \& Wilkins; 2012.

9. Premachandra BN, Winder WW, Hickson R, Lang S, Hollozy JO. Circulating reverese triiodothronine in humans during exercise. Eur. J. Appl. Physiol., 1981;47:281-288. https://doi.org/10.1007/BF00422473

10.Pakarinen A, Alen M, Häkkinen K, Komi P. Serum thyroid hormones, thyrotropin and thyroxine binding globulin during prolonged strength training. European Journal of Applied Physiology and Occupational Physiology, 1988;57(4):394-398. https://doi.org/10.1007/BF00417982

11.SimschC,Lormes W,PetersenKG,BaurS,LiuY,HackneyAC, et al. Training Intensity Influences Leptin and Thyroid Hormones in Highly Trained Rowers. Int J Sports Med, 2002;23:422-7. https://doi.org/10.1055/s-2002-33738

12.Poole DC, Wilkerson DP, Jones AM. Validity of criteria for establishing maksimal $\mathrm{O} 2$ uptake during rump exercise test. European Journal of Appl. Phys., 2007;102(4):403-410. https://doi.org/10.1007/s00421-007-0596-3

13.Sullo A, Brizzi G, Maffulli N. Deiodinating activity in the Brown adipose tissue of rats following short cold exposure after strenuous exercise. Physiology and Behavior, 2003;80:399-403. https://doi.org/10.1016/j.physbeh.2003.09.005

14.Galbo H. Hormonal and metabolic adaptations to exercise. New York: Thieme-Stratton Inc; 1983.

15.Kilic M, Baltaci AK, Gunay M, Gökbel H, Okudan N, Cicioglu I. The effect of exhaustion exercise on thyroid hormones and testosterone levels of elite athletes receiving oral zinc. Neuro Endocrinology Letters, 2006;27(1-2):247252.

16.Bosco C, Tihanyi J, Rivalta L, Parlato G, Tranquilli C, Pulvirenti G, et al. Hormonal Responses in Strenuous Jumping Effort. Jpn. J. Physiol., 1996;46:93-8. https://doi.org/10.2170/jjphysiol.46.93
17.Huang W-S, Yu M-D, Lee M-S, Cheng C-Y, Yang S-P, Chin H-ML, etal.EffectofTreadmillExerciseonCirculatingThyroid Hormone Measurements. Med Princ Pract, 2004;13:15-9. https://doi.org/10.1159/000074045

18.Beyleroglu M. The effects of maximal aerobic exercise on cortisol and thyroid hormones in male field hockey players. African Journal of Pharmacy and Pharmacology, 2011;5(17):2002-2006. https://doi.org/10.5897/AJPP11.229

19.Sowers JR, Raj RP, Hershman JM, Carlson HE, McCallum RW. The effect of stressful diagnostic studies and surgery on anterior pituitary hormone release in man. Acta Endocrinol. (Copenh), 1977;86:25-32. https://doi.org/10.1530/acta.0.0860025

20.Moore AW, Timmerman S, Brownlee KK, Rubin DA, Hackney AC. Strenuous, fatiguing exercise: relationship of cortisol to circulating thyroid hormones. Int. J. Endocrinol. Metab., 2005;1:18-24. https://pesquisa.bvsalud.org/portal/ resource/pt/emr-176826

21.Hesse V, Vilser C, Scheibe J, Jahreis G, Foley T. Thyroid hormone metabolism under extreme body exercise. Exp. Clin. Endocrinol., 1989;94(1/2):82-88. https://doi.org/10.1055/s-0029-1210883

22.Mason JW, Hartley LH, Kotchen TA, et al. Plasma thyroid-stimulating hormone response in anticipation of muscular exercise in the human. J. Clin. Endo. Metab., 1973;37(3):403-406. https://doi.org/10.1210/jcem-37-3-403

23.Koz M, Akgül MS, Atici E. The effects of exercise on the hormone secretion and regulation. Turkiye Klinikleri $J$. Physiother Rehabil-Special Topics, 2016;2(1):48-56.

24.GalboH,HummerL,PetersenIB,ChristensenNJ,BieN.Thyroid and testicular hormone responses to graded and prolonged exercise in man. Eur. J. Appl. Physiol., 1977;36:101-106. https://doi.org/10.1007/bf00423117

25.Dessypris A, Wager G, Fyhrquist F, Makinen T, Welin MG, Lamberg BA. Marathon run: effects on blood cortisol-ACTH, iodothyronines- TSH and vasopressin. Acta Endocrinol., 1980;95:151-157. https://doi.org/10.1530/acta.0.0950151

26.Sander M, Rocker L. Influence of marathon running on thyroid hormones. Int. J. Sports Med., 1988;9:123-126. https://doi.org/10.1055/s-2007-1024992

27.Terjung RL, Tipton CM. Plasma thyroxine and thyroidstimulating hormone levels during submaximal exercise in humans. Am. J. Physiol., 1971;220(6):1840-1845. https://oi.org/10.1152/ajplegacy.1971.220.6.1840

28.Schmid P, Wolf W, Pilger E, Schwaberger G, Pessenhofer H, Pristautz $\mathrm{H}$, et al. TSH, T3, rT3 and fT4 in maximal and submaximal physical exercise. Europ $J$ Appl Physiol, 1982;48:31-9. https://doi.org/10.1007/bf00421162

29. Semple CG, Thomson JA, Beastall GH. Endocrine responses to marathon running. Br. J. Sports Med., 1985;19(3):148-151. https://doi.org/10.1136/bjsm.19.3.148

30.Klubo-Gwiezdzinska J, Bernet VJ, Wartofsky L, Constantini N, Hackney AC. Exercise and thyroid function. Endocrinology of physical activity and sport. New York: Springer; 2013. https://doi.org/10.1007/978-1-62703-314-5_6

31.Opstad K. Circadian rhythm of hormones is extinguished during prolonged physical stress, sleep and energy deficiency in young men. Eur. J. Endocrinol., 1994;131:56-66. https://doi.org/10.1530/eje.0.1310056 
Information about the authors:

Mustafa S. Akgul; (Corresponding Author); Assoc. Prof.; http://orcid.org/0000-0002-9696-6541; mustafasakirakgul@karabuk. edu.tr; Hasan Dogan School of Physical Education and Sports, Karabuk University; Karabuk, 78050, Turkey.

Bilgehan Baydil; Prof;; http://orcid.org/0000-0002-9161-2381; bilgehan@kastamonu.edu.tr; Faculty of Sports Science, Kastamonu University; Kastamonu, 37150, Turkey.

\section{Cite this article as:}

Akgul MS, Baydil B. Thyroid hormone responses to acute aerobic exercise. Physical Education of Students, 2021;25(6):359363.

https://doi.org/10.15561/20755279.2021.0604

This is an Open Access article distributed under the terms of the Creative Commons Attribution License, which permits unrestricted use, distribution, and reproduction in any medium, provided the original work is properly cited http://creativecommons.org/licenses/by/4.0/deed.en

Received: 01.10.2021

Accepted: 03.11.2021; Published: 30.12.2021 